\title{
UNVEILING THE COMPLEX STRUCTURE OF TASMANIAN TEMPERATE FORESTS WITH MODEL-BASED TANDEM-X TOMOGRAPHY
}

\author{
Maciej J. Soja ${ }^{l, 2)}$, Susan C. Baker ${ }^{l)}$, Gregory J. Jordan ${ }^{l)}$, Arko Lucieer ${ }^{l)}$, Robert Musk ${ }^{3)}$, Lars M. H. \\ Ulander $^{4}$, Mark L. Williams ${ }^{2}$, and Richard J. White ${ }^{I)}$ \\ 1) University of Tasmania, Hobart, TAS, Australia \\ ${ }^{2)}$ Horizon Geoscience Consulting, Belrose, NSW, Australia \\ ${ }^{3)}$ Sustainable Timber Tasmania, Hobart, TAS, Australia \\ ${ }^{4)}$ Chalmers University of Technology, Göteborg, Sweden
}

\begin{abstract}
This paper presents the first results from model-based TanDEM-X tomography of a structurally complex temperate forest in Tasmania. Two tomographic profiles are shown and heights estimated using three-level model inversion are compared with similar metrics from airborne lidar scanning.
\end{abstract}

\section{INTRODUCTION}

The Australian island state of Tasmania features some of the world's most diverse and structurally complex temperate forests. Multiple endemic and ancient plant and animal species thrive on the island and some of the largest patches of the relatively rare temperate rainforests can also be found there. One of the most important components of Tasmania's forests is the tall eucalypt forests, which hosts the tallest flowering plants in the world, the mighty swamp gums (Eucalyptus regnans), reaching up to a height of $100 \mathrm{~m}$. Much of the tall eucalypt forests is used for wood and paper production, which can create conflicts between conservation and economic value of these forests.

Due to the vastness, remoteness, diversity and economic value of Tasmanian forests, remote sensing-based forest classification tools are useful for strategic conservation and management planning. Currently, broad-scale forest classification in Tasmania relies on either conventional vegetation mapping data (TasVeg) [1] for classification into broad vegetation categories or PI-type data [2]. PItype data, derived from interpretation of aerial photographs, predominantly classifies stands according to the density and age class of canopy eucalypts.

However, neither TasVeg nor PI-type data are accurate at classifying understory composition in wet eucalypt forests because the dense eucalypt canopy largely obscures understory vegetation. Since some types of understory vegetation, e.g., rainforest vegetation, are less common than others, e.g., sclerophyll, being able to classify the understory vegetation is important for conservation purposes. Thus, there is a need for accurate remote sensingbased classification tools, able to distinguish between different understory compositions. Differences in vegetation structure between common rainforest and wet sclerophyll tree species suggest there is scope for canopypenetrating remote sensing tools to provide tools for forest type classification.

Synthetic-aperture radar (SAR) uses active, radio- or microwave frequency signals for spatial imaging. SAR imagery is therefore daylight- and cloud-independent, and typically also foliage-penetrating [3]. Moreover, with a technique called SAR interferometry (InSAR), two SAR images acquired from slightly different angles can be used together to produce a height map, a so-called digital elevation model (DEM). InSAR is therefore a very promising tool for mapping of the vertical forest structure and significant efforts are made world-wide to make it an operational forest mapping tool.

In this paper, we will use data from the German twin-satellite InSAR system TanDEM-X, operating at X-band (wavelength of $3.3 \mathrm{~cm}$ ), to measure the maximal and median canopy heights and their scattering strengths. From these characteristics we will estimate vertical scattering profiles for Warra, a temperate forest test site in southern Tasmania. We will show that the estimated heights are correlated with similar metrics from airborne lidar scanning (ALS). We will also show different profiles obtained with the proposed technique and we will discuss its further applications.

\section{INVERSION METHOD}

The primary quantity measured by InSAR is the complex correlation coefficient:

(1) $\quad \tilde{\gamma}=\frac{\mathrm{E}\left[s_{1} s_{2}^{*}\right]}{\sqrt{\mathrm{E}\left[\left|s_{1}\right|^{2}\right] \mathrm{E}\left[\left|s_{2}\right|^{2}\right]}}$ 
where $s_{1}$ and $s_{2}$ are the two complex SAR images and $\mathrm{E}[\cdot]$ is the expectation value operator. The complex correlation coefficient is a measure of similarity between the two images: its phase represents their phase difference and its magnitude represents their degree of similarity (coherence).

In cases when temporal decorrelation between the two acquisitions is negligible and accurate pre-processing (including common band and wavenumber shift filtering and phase calibration) has been conducted, then the complex correlation coefficient can be modelled as a product of a complex-valued volumetric decorrelation $\tilde{\gamma}_{\mathrm{vol}}$, introduced by the distribution of scattering objects in the vertical direction, and a real-valued system decorrelation term $\gamma_{\text {sys }}$, introduced by system imperfections and thermal noise:

(2) $\tilde{\gamma}=\gamma_{\mathrm{sys}} \tilde{\gamma}_{\mathrm{vol}}$.

In this paper, we will use a theoretical model for volume decorrelation $\tilde{\gamma}_{\text {vol }}$, which will be fitted to volume decorrelation estimated from the complex correlation coefficient $\tilde{\gamma}$ measured by the TanDEM-X system.

Several past studies have shown that volumetric decorrelation can be modeled in boreal forests with only two infinitely thin scattering levels: ground and vegetation, the latter with gaps $[4,5]$. The proposed model was called two-level model (TLM) and it proved itself useful for forest height and canopy density mapping from TanDEM-X data in regions with known topography.

With their more diverse species composition, layered vertical structure, and a larger overall height, the temperate forests of Tasmania are structurally more complex than the boreal forests of Sweden. It is therefore reasonable to extend the TLM to a three-level model (3LM) by adding a second infinitely thin vegetation level, also with gaps. This leads to the following expression for volume decorrelation:

$$
\begin{aligned}
& \tilde{f}_{\mathrm{vol}}\left(z_{0}, h_{1}, h_{2}, v_{1}, v_{2}\right)= \\
& e^{i k_{z} z_{0}} \frac{1+v_{1} e^{i k_{z} h_{1}}+v_{2} e^{i k_{z} h_{2}}}{1+v_{1}+v_{2}}
\end{aligned}
$$

where $z_{0}$ is the ground topography, $h_{1}$ and $h_{2}$ are the elevations of the two vegetation levels above ground $\left(h_{2}>h_{1}\right), \mu_{1}$ and $\mu_{2}$ are vegetation-to-ground ratios, quantifying the fractional contribution of each vegetation level to the total backscattering, and $k_{z}$ is the vertical wavenumber. The vertical wavenumber is a system parameter quantifying its sensitivity to displacement in height. A perhaps more intuitive system parameter is height-ofambiguity (HOA), which is the height offset yielding a $2 \pi$-phase difference between the two images, and it is related to the vertical wavenumber as: $\mathrm{HOA}=2 \pi k_{z}^{-1}$.

In this paper, as in many previous publications on the TLM [4,5], we will assume that the ground topography $z_{0}$ is known from a digital terrain model (DTM), e.g., acquired by means of airborne lidar scanning. This type of terrain model is becoming more and more popular world-wide and future spaceborne lidar systems, like the upcoming NASA/JPL mission GEDI, will further improve the availability of such terrain information. Moreover, since ground topography is temporally stable in most forested areas, only one airborne lidar acquisition is needed, and the subsequent forest mapping can be conducted from space with all the coverage and acquisition frequency that satellites have to offer.

With the assumption of known $z_{0}$, the $3 \mathrm{LM}$ requires four parameters to model one complex quantity. Therefore, at least two measured complex correlation coefficients are required to be able to obtain a solvable equation system. In this paper, we will achieve this by neglecting temporal change in the studied forest and using multi-temporal TanDEM-X acquisitions. Another approach is to use TanDEM-X data acquired in the alternating-bistatic mode, which provides two unique measurements per acquisition, but such data were not available for this study.

The inversion will be conducted by numerical minimization of the mean-square difference between the modelled and measured complex correlation coefficients:

$$
\sum_{i=1}^{N_{a c q}}\left|\tilde{f}_{\mathrm{vol}}\left(h_{1}, h_{2}, \mu_{1}, \mu_{2}\right)-\tilde{\gamma}_{\mathrm{vol}, i}\right|^{2}
$$

where $\tilde{\gamma}_{\mathrm{vol}, i}$ is the measured volume decorrelation for acquisition $i$, obtained by dividing the measured complex correlation coefficient by an estimate of the system decorrelation.

The fractional contributions $\eta_{i}$ of each level $i$ to the total backscattered signal will be calculated as: 

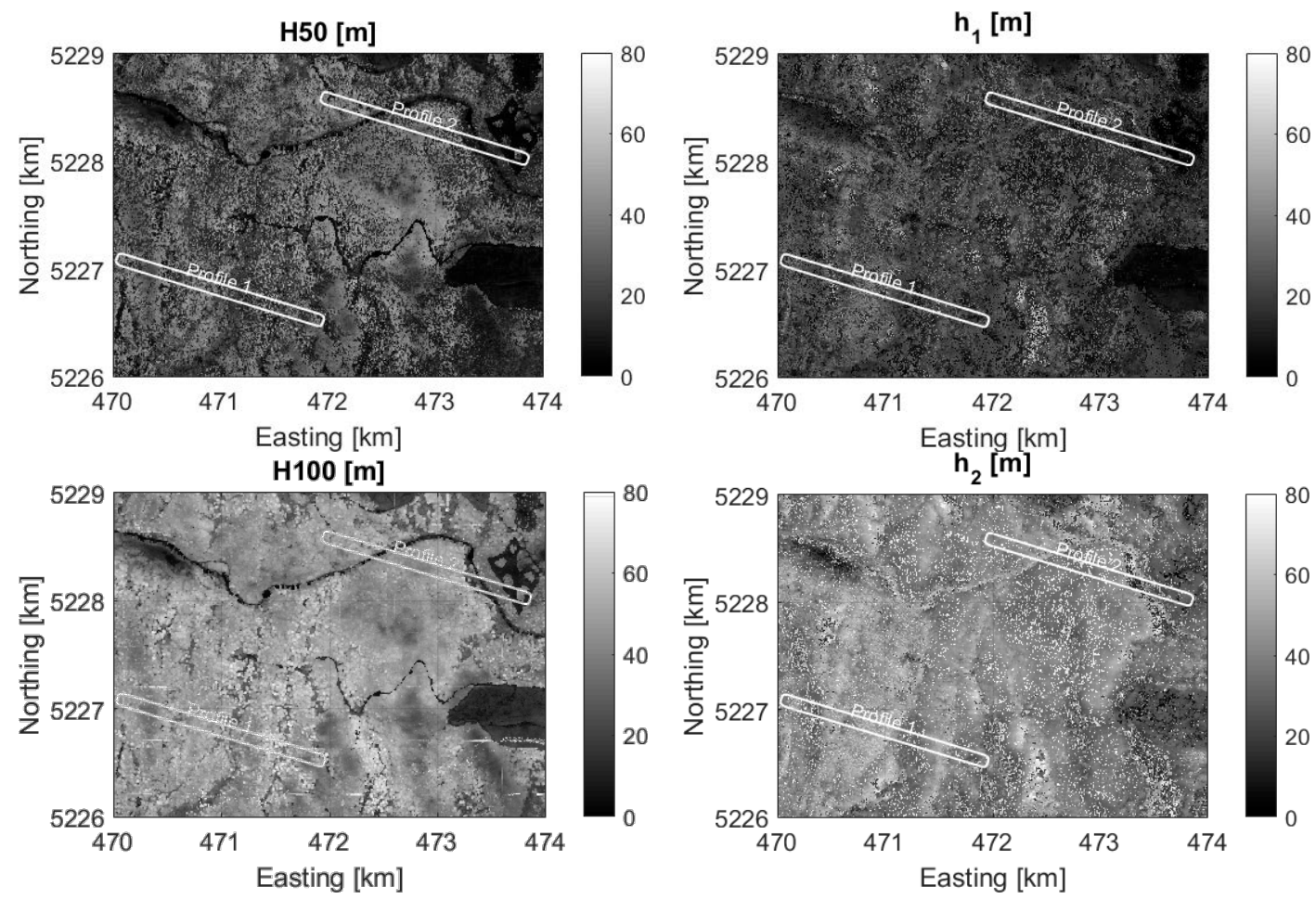

Figure 1: Comparison between H50 and H100 measured with airborne lidar scanning and $h_{1}$ and $h_{2}$ obtained from 3LM inversion of multi-temporal TanDEM-X data. All images are in UTM55N coordinates.

Profile 1 is in the south-western part of the area and profile 2 is in the north-eastern part of the area.

$$
\begin{aligned}
& \eta_{0}=\left(1+\mu_{1}+\mu_{2}\right)^{-1} \\
& \eta_{1}=\mu_{1}\left(1+\mu_{1}+\mu_{2}\right)^{-1} \\
& \eta_{2}=\mu_{2}\left(1+\mu_{1}+\mu_{2}\right)^{-1}
\end{aligned}
$$

where $\eta_{0}$ is the contribution of the ground level located at an elevation $h_{0}=0$. From the three $\left(h_{i}, \eta_{i}\right)$ pairs, vertical backscatter profiles can be reconstructed using linear interpolation.

\section{EXPERIMENTAL DATA}

The study landscape is located at the Warra Long-Term Ecological Research site. The Warra Tall Eucalypt Supersite is one of ten study landscapes that comprise the Australiawide Terrestrial Ecosystem Research Network. The $5 \mathrm{~km} \times 5 \mathrm{~km}$ focal landscape is part of the TERN AusCover network of remote sensing datasets. Annual rainfall is approximately 1700 $\mathrm{mm}$ and elevation of the surveyed area is between 60 and $437 \mathrm{~m}$ above sea level.

The vegetation is dominated by tall lowland Eucalyptus obliqua forests, often with dense multi-layered understories. The understory vegetation ranges from mixed forest, dominated by rainforest understory species such as Nothofagus cunninghamii and Atherosperma moschatum to wet sclerophyll forest, dominated by sclereophyllous species such as

Pomaderris apetala and Nematolepis squamea. However, mixtures of rainforest and sclerophyll species are common. Major determinants of understory species composition and structure include fire history, soil fertility and drainage.

InSAR data were acquired with the German twin-satellite system TanDEM-X. Four HHpolarized acquisitions made in the stripmap mode on 2011/01/11, 2011/10/13, 2012/03/26, and $2013 / 01 / 28$ were used in this study. All acquisitions were made from the same descending orbit, with a nominal incidence angle of $46^{\circ}$ and HOAs of $42 \mathrm{~m}, 69 \mathrm{~m}, 132 \mathrm{~m}$, and $66 \mathrm{~m}$, respectively for each acquisition. InSAR data were processed using software from GAMMA Remote Sensing.

Small-footprint ALS data were acquired over the test site between $30^{\text {th }}$ and $31^{\text {st }}$ of May 2014 with the RIEGL LMS-Q560 sensor, from an altitude of about $500 \mathrm{~m}$. The nominal point density was roughly 20 points per square meter. From the ALS point clouds, two metrics were estimated on a $10 \mathrm{~m} \times 10 \mathrm{~m}$ grid: H50 and $\mathrm{H} 100$, i.e., the $50^{\text {th }}$ percentile (median) and the $100^{\text {th }}$ percentile (maximum) of all returns classified as vegetation returns. 
Profile 1

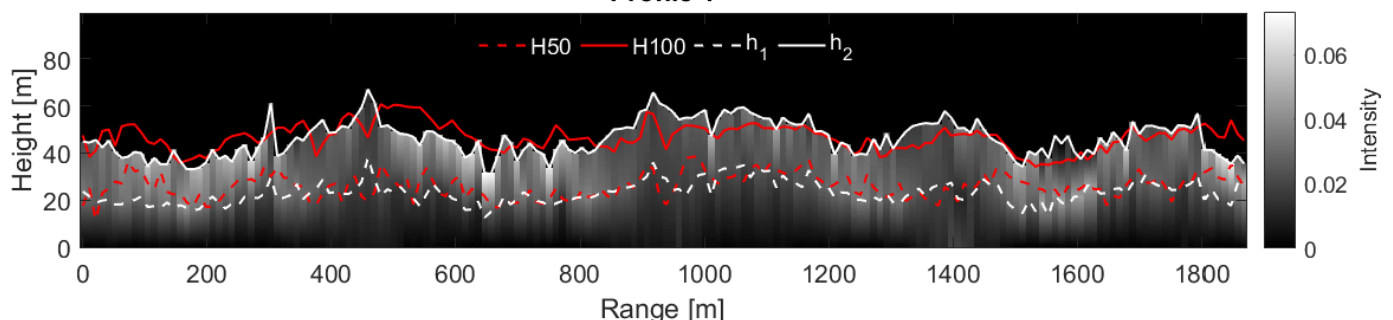

Profile 2

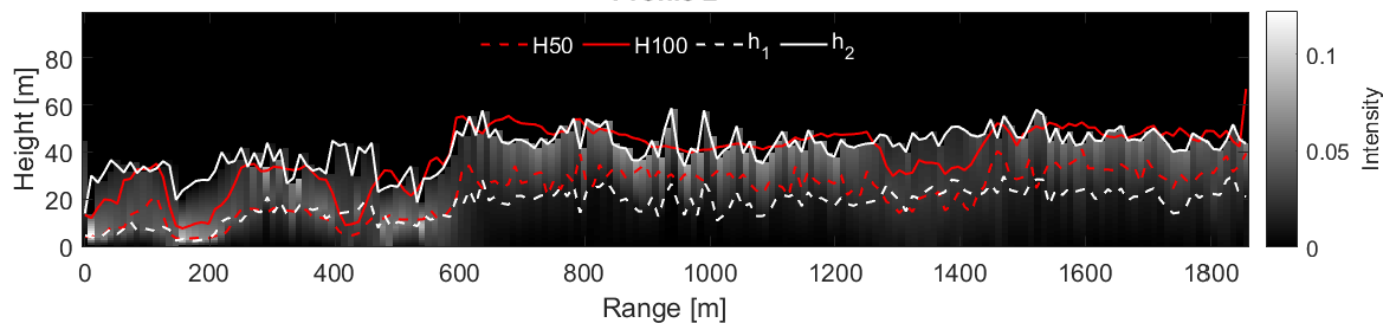

Figure 2: Examples showing three backscatter profiles along the transects shown in Figure 1, together with H50 and H100 from ALS and $h_{1}$ and $h_{2}$ from 3LM inversion. The profile locations are outlined in Figure 1 and the range is measured from the south-east end.

The DTM was derived from lidar data acquired using a fixed-wing aircraft in February 2011 using an Optech ALTM Gemini sensor. The pulse density was estimated to be greater than 2 pulses per square meter.

\section{RESULTS}

Figure 1 compares the estimated heights $h_{1}$ and $h_{2}$ with similar lidar metrics H50 and H100. Good agreement is observed for most areas.

Figure 2 shows two vertical backscatter profiles obtained along the transects shown in Figure 1, together with $h_{1}, h_{2}, \mathrm{H} 50$, and H100. The upper vegetation level height $h_{2}$ agrees generally well with the maximum height from lidar (H100), although there are some areas of disagreement, both where $h_{2}$ is higher and lower than H100. Note that in some cases when $h_{2}$ is larger than H100, the profile shows a low intensity around $h_{2}$, so the low-vegetation area is still correctly detected. The agreement between $\mathrm{H} 50$ and $h_{1}$ is similar in most areas, although we can observe that for ranges around $900 \mathrm{~m}$ and $1600 \mathrm{~m}$ for profile $2, h_{1}$ is consistently lower than H50. It appears that these regions in profile 2 show a denser forest.

\section{CONCLUSIONS}

We have shown and briefly analyzed X-band tomographic profiles over a structurally complex temperate forest. The results clearly show the potential of the technique, although much further work is needed. The obtained tomographic profiles provide an interesting insight into the scattering distribution and perhaps also into the vertical structure of the forest, but they are also influenced by moisture variability in the forest. Furthermore, the current approach assumes that the studied forest has not changed between the first and last acquisitions (i.e., over two years), which is a significant simplification. Qualitative and quantitative validation against in situ vegetation classification and lidar measurements will be conducted next. Moreover, the proposed approach will be tested on TanDEM-X data acquired in the alternating-bistatic mode.

\section{ACKNOWLEDGEMENTS}

The authors would like to thank German Aerospace Center (DLR) for the TanDEM-X data provided within project XTI_VEGE0515.

\section{REFERENCES}

[1] Department of Primary Industries, Parks, Water and Environment. TASVEG 3.0, Released November 2013. Tasmanian Vegetation Monitoring and Mapping Program, Resource Management and Conservation Division.

[2] Stone, M. G. "Forest-type mapping by photointerpretation: A multi-purpose base for Tasmania's forest management," Tasforests, 1998, pp. 15-32

[3] Oliver, C., and Quegan, S., Understanding Synthetic Aperture Radar Images, SciTech Publishing, 2004

[4] Soja, M. J., Persson, H. J., and Ulander, L. M. H., "Estimation of forest height and canopy density from a single InSAR correlation coefficient," IEEE Geosci. Remote Sens. Lett., vol. 12, no. 3, pp. 646-650, Mar. 2015

[5] Soja, M. J., Persson, H. J., and Ulander, L. M. H., "Estimation of forest biomass from two-level model inversion of single-pass InSAR data," IEEE Trans. Geosci. Remote Sens., vol. 53, no. 9, pp. 5083-5099, Sep. 2015 